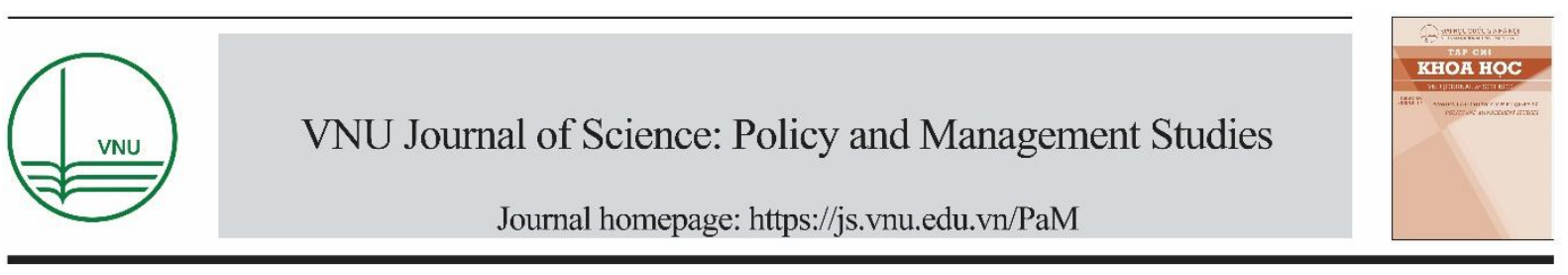

Original Article

\title{
Charles Sanders Pierce's Classification of the Sciences: History, Content and Significance
}

\author{
Le Viet Hung* \\ Hanoi University of Science and Technology, 1 Dai Co Viet, Hai Ba Trung, Hanoi, Vietnam
}

Received 17 December 2019

Revised 09 March 2020; Accepted 15 March 2020

\begin{abstract}
This paper articulates the historical context, systematise, gives out critical judgements, contributes to improvement of Pierce's classification of sciences and suggests the benefits and application of Pierce in the theory of science, management and policy of science. Research methods include: literature reviewing of original papers of Pierce and secondary literatures of other scholars; logic analysis examines the internal coherence of Pierce's classification, historical method puts Pierce's classification in scientific, historical and sociological context to clarify its origin. The paper outlines reasons and importance for investigation in the introduction; then it outlines the history of pre-Pierce scientific classification, analyses macro- and micro-historical circumstances leading to the introduction of Pierce's classifications, the content of Pierce's classifications and their significance for culture, scientific research, and scientific research management.

Keywords: Classification of science, philosophy of science, theory of science, management of science, Charles Sanders Pierce.
\end{abstract}

\footnotetext{
* Corresponding author.

E-mail address: hung.leviet@ hust.edu.vn
}

https://doi.org/10.25073/2588-1116/vnupam.4209 


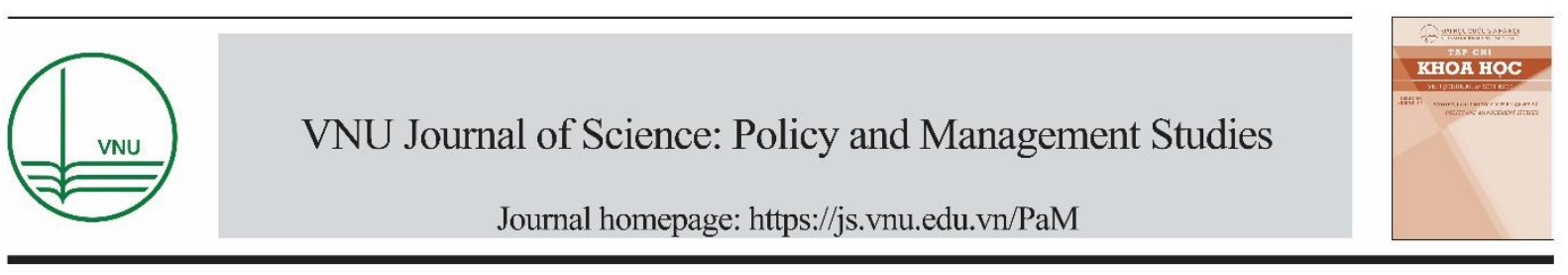

\title{
Phân loại khoa học của Charles Sanders Pierce: Lịch sử, nội dung và ý nghĩa
}

\author{
Lê Việt Hùng* \\ Truoòng Đại học Bách Khoa Hà Nội, 1 Đại Cồ Việt, Bách Khoa, Hai Bà Trung, Hà Nội, Việt Nam \\ Nhận ngày 17 tháng 12 năm 2019 \\ Chỉnh sửa ngày 09 tháng 3 năm 2020; Chấp nhận đăng ngày 15 tháng 3 năm 2020
}

\begin{abstract}
Tóm tắt: Bài viết trình bày lịch sử ra đời, hệ thống hóa, đưa ra các đánh giá có tính phê phán, góp phần hoàn thiện bảng phân loại của Pierce, vạch ra ý nghĩa nhận thức và ý nghĩa ứng dụng của chúng trong khoa học luận và quản lý khoa học công nghệ. Các phương pháp được sử dụng bao gồm: nghiên cứu tư liệu, dùng các tư liệu sơ cấp một cách có phê phán (bản gốc tư liệu của Pierce) và tài liệu thứ cấp của các học giả nghiên cứu về Pierce; phương pháp logic nhằm đánh giá tính nhất quán của các bảng phân loại khoa học của Pierce; phương pháp lịch sử nhằm làm rõ bối cảnh ra đời bảng các bảng phân loại khoa học của Pierce. Bài viết nêu ra lý do và tầm quan trọng của nghiên cứu, phác thảo sơ lược lịch sử phân loại khoa học trước Pierce, phân tích hoàn cảnh lịch sử (vĩ mô và vi mô) dẫn đến sự ra đời bảng phân loại của của Pierce, nội dung các bảng phân loại của Pierce và ý nghĩa của chúng đối với văn hóa, nghiên cứu khoa học và quản lý nghiên cứu khoa học.
\end{abstract}

Tù khóa: Phân loại khoa học, triết học khoa học, khoa học luận, quản lý khoa học, Charles Sander Pierce.

\section{Mở đầu}

Peirce, Charles Sanders (1839 - 1914) là một nhà bác học, nhà khoa học đa tài, một nhà tư tưởng lỗi lạc và độc sáng của Mỹ. Ông nổi tiếng như là người sáng lập ra chủ nghĩa dụng hành (pragmaticism) Mỹ và có những đóng góp lớn cho logic học, là người mở ra môn tín hiệu học, đồng thời có nhiều đóng góp khác nhau cho nhiều ngành khoa học như toán học, vật lý học, trắc địa, phổ học, thiên văn học; các ngành khoa học xã hội như tâm lý học, nhân chủng học, lịch sử và kinh tế học cùng nhiều ngành khác trong khoa học xã hội và nhân văn $[1,2]$. Pierce rất chú ý đến vấn đề phân loại khoa học, chúng chiếm một mối quan tâm và công sức lớn trong quá trình nghiên cứu và xây dựng hệ thống khoa học của ông [1]. Tuy nhiên, giới nghiên cứu và độc giả ở Việt Nam gần như ít biểt đến bảng phân loại này của Pierce mà chỉ giới thiệu chung về Pierce trong các công trình về triết học.

Từ thế kỷ 17 đến nay, sự bùng nổ ngày càng nhanh với quy mô ngày càng lớn của khoa học và công nghệ, sự sinh thành nảy nở của rất nhiều hiệp hội khoa học, tạp chí chuyên ngành, sự phân ngành và tích hợp, sự xuất hiện các ngành khoa học mới đòi hỏi một sự phân loại rõ ràng, khoa học, tường minh, logic. Điều này không chỉ có ý nghĩa nhận thức với ngành khoa học học, ý nghĩa văn hóa đối với nhận thức chung của con người về khoa học mà còn quan trọng với quản lý và 
hoạch định chính sách khoa học. Trong bài này, tác giả viết về một trong các bảng phân loại khoa học quan trọng trong khoa học về phân loại khoa học: các bảng phân loại khoa học của Pierce. Qua đó đánh giá, chỉ ra những ý nghĩa khoa học và ứng dụng của phân loại này.

\section{Lịch sử phân loại khoa học trước Pierce}

Nhà khoa học luận Liên Xô Kedrov Bonifatii (1903 - 1985) cho rằng phân loại khoa học đã xuất hiện từ Hy Lạp cổ đại cùng với khoa học [3]. Aristotle và một số người khác chia tri thức của nhân loại tương ứng với mối đối tượng nghiên cứu thành 3 loại: tri thức về tự nhiên (vật lý học), tri thức về xã hội (đạo đức học), tri thức về tư duy (logic học) có ảnh hưởng lớn đến sự phát triển của phân loại học khoa học về sau (Pierre Gassendi (1592 - 1655) giữ nguyên phân loại này) [3].

Thời Trung Cổ, dưới ảnh hưởng của Giáo Hội, bộ môn thần học có một vị trí đặc biệt trong phân loại khoa học và giáo dục, và các môn học thế tục được chia thành 7 môn nghệ thuật tự do (liberal arts). Nhìn chung thời kỳ này không có đóng góp đáng kể với sự phân loại khoa học vì sự vận dụng hời hợt phân loại của Aristotle và sự thống trị của chủ nghĩa kinh viện trong học thuật [3].

Vào thời kỳ Phục Hưng và chủ nghĩa nhân văn, Francis Bacon (1561 - 1626) phân loại khoa học dựa vào ba quan năng: trí nhớ, trí tưởng tượng, và lý trí, từ đó phân chia khoa học thành 3 nhánh tương ứng: lịch sử, thi ca và triết học; mỗi nhánh lại có các rẽ nhánh xa hơn [3-5]. Thomas Hobbes (1588-1679) nỗ lực thống nhất các nguyên tắc phân loại chủ quan và khách quan của Bacon, ông chia khoa học thành khoa học diễn dịch (deductive sciences) và khoa học quy nạp (inductive sciences); là một nhà duy lý và theo thuyết cơ học, ông coi phương pháp toán học là phổ quát, đặt hình học đứng đầu nhánh khoa học và vật lý đứng đầu nhánh quy nạp. Ở Hobbes ta có thể thấy hạt nhân của tiêu chí phân loại từ trừu tượng đến cụ thể, từ định lượng đến định tính [3]. Lemery (1645 - 1715) phát triển thêm phân loại về khoa học tự nhiên thành 3 nhánh: khoáng vật học, thực vật học và động vật học. John Locke $(1632$ - 1704) phục hồi khuynh hướng phân loại cổ điển của Aristotle, Locke chia khoa học thành: vật lý học, khoa học thực hành và logic học [3].

Các học thuyết nguyên tử luận dẫn đến ý tưởng về tiêu chí phân chia khoa học một cách khách quan theo cấp độ phức tạp của vật chất (phân tử ở Gassendi, nhóm các hạt nguyên thủy ở Robert Boyle (1627 - 1691)). Ở Anh, John Wilkins (1614-1672) đi từ các khái niệm và biểu tượng cơ bản như là điểm xuất phát để phân loại khoa học [3].

Các nhà bách khoa Pháp như Denis Diderot (1713-1784) và $D^{\prime}$ Alembert (1717-1783) đã sử dụng các nguyên tắc và lược đồ phân loại của Bacon để soạn cây thư mục "Encyclopaedial Tree' cho từ điển bách khoa Encyclopédie với các thay đổi bổ sung chi tiết. Lomonossov (17111765) và Kozielsky phát triển những ý tưởng phân loại dựa trên thuyết nguyên tử xa hơn vào thế kỷ 18 [3].

\section{Phân loại học khoa học thế kỷ 18}

Saint-Simon (1760-1825) là người đầu tiên phát triển rõ ràng khuynh hướng phân loại khách quan (theo khách thể) từ đơn giản và chung đến phức tạp và chi tiết [3]. Auguste Comte (1798 1857), học trò của Simon đã dùng các ý tưởng của ông, đưa ra 6 loại khoa học căn bản (lý thuyết, trừu tượng) theo thứ bậc: Toán học, Thiên văn học, Vật lý học, Hóa học, Sinh lý học, Xã hội học (Xã hội học được bồ sung như một phân loại riêng biệt). Comte còn đưa ra 3 giai đoạn của sự phát triển nhận thức khoa học: Giai đoạn thần học, giai đoạn siêu hình học và giai đoạn thực chứng.

Jeremy Bentham (1748 - 1832), trong một phụ đính của cuốn Chrestomathia (1817), đã đưa ra một phân loại học dựa trên nguyên lý ích lợi (phân loại theo mức độ lợi ích giảm dần hoặc tăng dần), và sửa đổi "cây thư mục" dựa trên mô hình Bacon của D'Alembert [4]. Sau khi Bentham mất, William Whewell (1794 - 1866) đề ra một phân loại khoa học dựa trên các ý niệm chủ đạo, chẳng hạn khái niệm về Không gian là khái niệm căn bản tương ứng với môn Hình học, 
chuyển động với môn Động học v.v..; với mỗi ý niệm chủ đạo, có một bộ môn khoa học tương ứng [4]. Whewell đã kết hợp các nguyên tắc chủ quan với khách quan, Pierce cũng nhận ảnh hưởng này từ Whewell.

Trong khi những phân loại của Anh phụ thuộc vào chuyên môn hóa và phân chia lao động thì phân loại khoa học ở Pháp gắn bó mật thiết với thời đại của Napoleon. Trong bối cảnh này, André-Marie Ampère (1775-1836) và Auguste Comte (1798-1857) đã đưa ra bảng phân loại khoa học của họ. Ampère (1834) đã phân chia khoa học theo đối tượng nghiên cứu là vật chất hay tinh thần thành khoa học về vũ trụ/thế giới (sciences cosmologiques) và khoa học về tinh thần/tâm trí (sciences noologiques) [3].

Tuy có lịch sử lâu dài từ thời Cổ Đại đến thế kỷ 18, nhưng phân loại khoa học chỉ thực sự phát triển từ thế kỷ 19 , đặc biệt từ những năm 1820 trở đi, dưới bối cảnh khoa học và xã hội đặc thù. Đó cũng là tiền đề cho khoa học phân loại về khoa học của các nhà phân loại học thế kỷ 19 trong đó có Pierce, ra đời. Chúng ta sẽ xem xét hoàn cảnh này ở phần 3.1 .1 bên dưới.

\section{Phân loại khoa học của Pierce}

\subsection{Hoàn cảnh ra đời của bảng phân loại khoa hoc của Pierce}

3.1.1. Bối cảnh vĩ mô về xã hội và khoa học thế kỷ 19

Thế kỷ 19 là sự nở rộ của phân loại khoa học, các tác giả lớn của phân loại khoa học từ Jeremy Bentham đến André-Marie Ampère, từ William Whewell dến August Comte, Herbert Spencer, Wilhelm Wundt và Karl Pearson, đó là chỉ mới điểm danh những nhà phân loại học được Peirce biết rõ; có những người trong số họ đã ảnh hưởng đến phân loại học khoa học của Peirce [4]. Hầu hết các văn bản phân loại khoa học của thế kỷ 19, chẳng hạn như phân loại khoa học của Comte mở đầu bằng việc phê phán sự phân loại khoa học dựa trên "sự phân chia tùy tiện 3 quan năng của tâm trí và ... không phù hợp với sự phát triển của khoa học mới".
Vào thế kỷ 19, việc phân loại khoa học đã trở nên ngày càng quan trọng trong bối cảnh nhiều chuyên ngành khoa học được chuyên môn hóa. Sự chuyên biệt hóa các khoa học và sự nổi lên của các bộ môn khoa học mới đòi hỏi sự thỏa hiệp giữa các khoa học với nhau về vấn đề phân ranh giới giữa các ngành. Đòi hỏi này cung cấp một ý nghĩa nhận thức luận rõ rệt cho việc tìm hiểu về phân loại khoa học.

Là một thiết chế xã hội có hệ giá trị riêng và có sự tự trị ngày càng tăng trong xã hội, khoa học bắt đầu có nhu cầu củng cố bằng việc thiết lập các quy tắc hành chính và quản trị riêng của mình. Các nhu cầu tiêu chuẩn hóa khoa học, nhu cầu giao tiếp khoa học quốc tế thông qua các mạng lưới tạp chí khoa học mới xuất hiện, các diễn ngôn chính trị về quốc tế hóa khoa học đã đồng hợp tạo nên một môi trường, một hợp lực thúc đầy sự quan tâm đến vấn đề phân loại khoa học [4]. Đây là động lực thứ hai cho phân loại học khoa học phát triển: nhu cầu hành chính quản trị khoa học.

Nhu cầu nhận thức luận và nhu cầu hành chinh quản trị đã khiến phân loại học khoa học thế kỷ 19 trở nên một bộ môn khá độc lập và một vấn đề khoa học có tính thời sự cùng nhiều lý thuyết phân loại khoa học. Alex Csiszar (2010) $[4,6]$ gọi đây là "khoảnh khắc phân loại" trong lịch sử khoa học . Sự quan tâm đến phân loại học và các bảng phân loại khoa học của Pierce ra đời trong hoàn cảnh lịch sử như vậy.

\subsubsection{Các mối quan hệ cá nhân và sự nghiệp khoa hoc của Pierce}

Pierce sinh ra trong một gia đình trí thức; cha ông - Benjamin Peirce (1809 - 1880) là một nhà toán học hàng đầu của Hoa Kỳ đương thời, giáo sư Toán và Thiên văn học tại đại học Harvard. Cha ông đã dạy dỗ, thảo luận, trao đổi với Pierce từ nhỏ và có một ảnh hưởng vô cùng lớn lên tài năng của Pierce $[1,2]$. Sau này ông nói "Cha đã giáo dục tôi, và nếu tôi bất kỳ thành quả gì thì đó là nhờ công ơn của cha" [2].

Pierce học đọc và viết theo một cách riêng. Ông đọc từ sớm các tác phẩm bách khoa thư và các chủ đề khác ngoài khóa học thông thường. Pierce bộc lộ một niềm đam mê mãnh liệt với các 
bài toán đố, các thế cờ, ngôn ngữ mã hóa. Vào 8 tuổi ông tự học hóa học và tự tạo ra phòng thí nghiệm của riểng mình. 13 tuổi ông đọc tác phẩm "Elements of Logic" của Whately. Cha ông hiếm khi nào không chia sẻ các nguyên lý và định lý toán học với ông mà ngược lại, ông thường trình bày chúng kèm theo các vấn đề, bảng biểu, ví dụ và khích lệ ông tự tìm ra các nguyên lý cho chính mình [2]. Điều này góp phần vào sự độc lập tư duy và tạo tiền đề cho những kiến giải độc sáng của Pierce về khoa học sau này.

Khi vào Đại học Harvard (1855), ông tiếp tục được cha hướng dẫn về Toán học, và vào thời điểm này thì các vấn đề Toán học mà họ trao đổi vượt quá tầm hiểu biết của anh trai ông, người mà cũng có ý định trở thành nhà toán học [2]. Có thể nói, tri thức về Toán học được rèn giũa từ cha ông đã giúp ông thấy được vai trò của Toán học, và sau này vị trí của Toán học cũng được đặt ở một vị trí đặc biệt trong hệ thống phân loại khoa học của ông. Những suy tư của ông về mối quan hệ giữa logic, toán học, triết học và các môn khoa học còn lại chịu những ảnh hưởng từ người cha.

Ở Đại học Harvard, ông có hứng thú với triết học và đọc các tác phẩm của Schiller và Kant (Ổng gần như học thuộc lòng cuốn "Phê phán lý tính thuần túy" của Kant. Chính kiệt tác của Kant đã đưa ra những gợi ý về "kiến trúc" của khoa học (tương tự như Kant đã phác ra một "kiến trúc" của triết học (siêu hình học)) [1,2]. Mối quan hệ tốt đẹp của ông với William James, nhà tâm lý học và triết gia theo chủ nghĩa thực dụng Mỹ, đã giúp đỡ ông trong con đường nghiên cứu học thuật lẫn đời tư.

Sau khi tốt nghiệp đại học, ông làm việc ở Cơ quan Khảo sát Bờ biển của Hoa Kỳ. Vào khoảng thời gian đó ông dành 6 tháng để học kỹ thuật phân loại với nhà sinh học và địa lý học người Thụy Sĩ Luious Agassiz (1807 - 1873), điều này đã ảnh hưởng đển tư duy và hứng thú về phân loại học của Pierce (bảng phân loại khoa học chi tiết của Pierce năm 1902 áp dụng phân loại học sinh học (biological taxa) của Agassiz) . Ổng tiếp tục lấy các bằng cấp về hóa học và bằng thạc sĩ nghệ thuật ở Đại học Harvard. Ông có các bài giảng tại Harvard về triết học của khoa học, tụ họp với câu lạc bộ các triết gia, giảng dạy logic học. Từ năm 1869 đến năm 1872, ông làm trợ lý Đài Quan sát Harvard và sau đó xuất bản cuốn sách Photometric Researches (1878). Những năm sau đó ông làm nhiều công việc liên quan đến đo đạc, đo lường và thí nghiệm khoa học trong nhiều lĩnh vực như phổ học (spectroscopy), thăm dò trọng lực (gravimetry), trắc địa (geodesy), hóa học và tâm lý học thí nghiệm (experimental psychology) [1, 2]. Làm việc và nghiên cứu đa dạng các chủ đề khiến cho Pierce trở thành một nhà uyên bác (a polymath), tạo điều kiện thuận lợi cho việc tổng hợp và phân tích khoa học như một toàn thể.

Bên cạnh mặt thuận lợi, Pierce cũng gặp không ít khó khăn trong đời sống học thuật. Do mối ác cảm từ một số lãnh đạo đại học Harvard, ông đã không thể kiếm được một biên chế tại trường này [1]. Ông chỉ nổi tiếng sau khi mất và do không xuất bản chính thức các tác phẩm khoa học nhiều mà chủ yếu giữ ở dạng bản thảo nên nhiều tư tưởng của ông các học giả thế hệ sau mới khai thác. Đó cũng là một nguyên nhân khiến các công trình của ông, trong đó có phân loại khoa học bị chìm trong quên lãng một thời gian.

Có thể nói, học vấn, môi trường học thuật thuận lợi từ gia đình, đồng nghiệp hứng thú và thiên tư riêng của Peirce đã góp phần định hình phân loại học khoa học của Pierce, và sự bất lợi mà Pierce gặp phải cũng kiềm hãm sự phổ biến những tư tưởng lớn của ông về phân loại khoa học.

\subsection{Tiêu chí, cách thức phân loại khoa học của Pierce}

Cũng như các nhà phân loại khoa học lớn khác, Pierce không nhìn khoa học như một tập hợp hỗn độn các chuyên ngành mà như một tổng thể thống nhất và được chia tách theo nhiều lát cắt khác nhau, chúng ta gọi là tiêu chí phân loại. Pierce phân loại khoa học theo các tiêu chí:

Mức độ chuyên biệt hóa (degree of specialization) (1889), mức độ trùu tương của đối tượng nghiên cứu (1898), muc đích căn bản của nghiên cứu (1903). Dựa vào phân loại sinh học của Agassiz, Pierce đưa các khái niệm như Chi, Loài, Giống, Họ... vào hệ thống phân loại 
của mình thể hiện các tiêu chí như mục đích chung, đối tượng chung, mức độ tự trị của chuyên ngành.v..v. Dựa vào các tiêu chí đó,
Pierce cụ thể hóa thành các sơ đồ và bảng phân loại, như dưới đây.

3.3. Các so đồ và bảng phân loại khoa học của Pierce So đồ phân loại khoa học của Pierce 1889 [7-8].

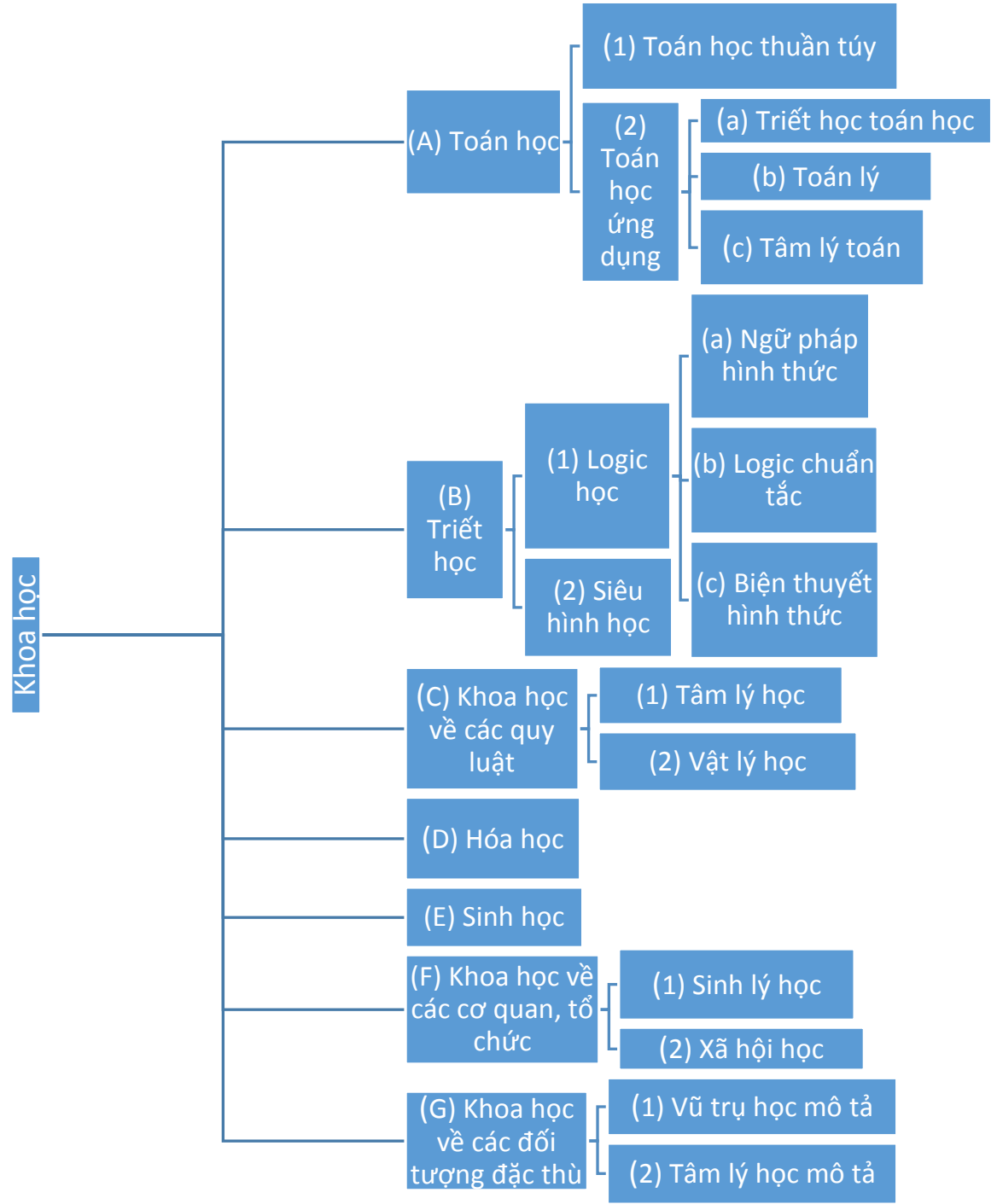

Theo mức độ chuyên biệt hóa, ta có thể thấy, theo Pierce thì Toán học là khoa học tổng quát nhất, chỉ nghiên cứu các đối tượng mang tính giả thuyết của tâm trí con người (không quan sát thực kiện). Điểm đặc biệt là Pierce xếp Toán học cao hơn Triết học trong thang phổ quát, Triết học khảo sát và phân tích logic đối với các tập hợp chung về thực kiện.

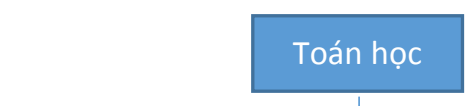

Triết học

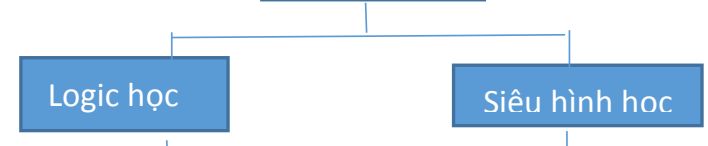

Các khoa học cụ thể

\begin{tabular}{|l|l|}
\hline Tâm học & \\
\hline Tâm lý học quy luật & \\
\hline Vật lý học \\
\hline Vật lý học quy luật
\end{tabular}


Lược đồ phân loại năm 1898 [7, 8].

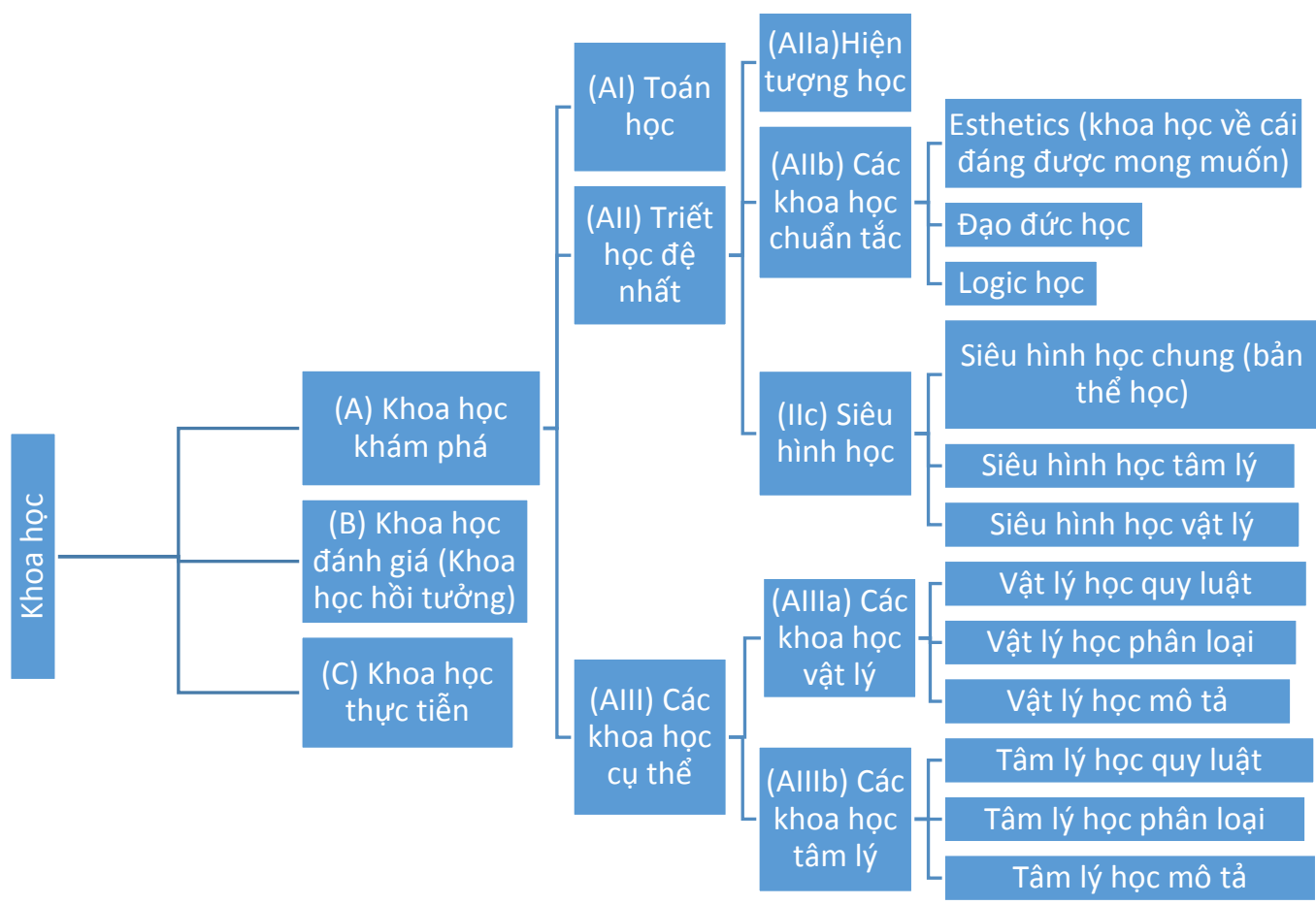

Sơ đồ phân loại khoa học của Pierce năm 1902-1911 [7, 9].

Phân loại khoa học dựa theo cách phân loại sinh học. [7]

\begin{tabular}{|l|l|l|l|}
\hline Tên & $\begin{array}{l}\text { Đặc điểm } \\
\text { (Bản phân loại khoa học chi }\end{array}$ & $\begin{array}{l}\text { Đặc điểm } \\
\text { (Bản sử dụng tại học viện Carnegie, } \\
1902)\end{array}$ & $\begin{array}{l}\text { Ví dụ } \\
\text { (Các ví dụ là của bản } \\
\text { Carnegie 1902) }\end{array}$ \\
\hline
\end{tabular}




\begin{tabular}{|c|c|c|c|}
\hline & $\begin{array}{l}\text { tiết (trong Minute Logic, } \\
\text { 1902) }\end{array}$ & & \\
\hline $\begin{array}{l}\text { Nhánh của } \\
\text { khoa học } \\
\text { (Branch of } \\
\text { science) }\end{array}$ & $\begin{array}{l}\text { Các nhánh khoa học khác biệt } \\
\text { nhau ở mục đích cơ bản. }\end{array}$ & $\begin{array}{l}\text { Trong một nhánh khoa học, các nhà } \\
\text { khoa học có cùng một động lực hoạt } \\
\text { động, mặc dù các nhà nghiên cứu } \\
\text { trong các lớp (class) khác nhau } \\
\text { dường như sống trong một thế giới } \\
\text { khác nhau }\end{array}$ & $\begin{array}{l}\text { Ba nhánh khoa học } \\
\text { trong phân loại của } \\
\text { Pierce: Khoa học } \\
\text { Khám phá, khoa học } \\
\text { Hồi tưởng và khoa } \\
\text { học Thực hành. }\end{array}$ \\
\hline $\begin{array}{l}\text { Lớp của khoa } \\
\text { học (Class of } \\
\text { science) }\end{array}$ & $\begin{array}{l}\text { Các lớp khoa học khác nhau } \\
\text { có sự khác biệt căn bản trong } \\
\text { quan sát. Các quan sát trong } \\
\text { một lớp khoa học (chẳng hạn } \\
\text { các khoa học vật lý và tâm lý } \\
\text { không thể tạo ra loại thông tin } \\
\text { mà lớp khoa học khác (chẳng } \\
\text { hạn Toán học) cần cho quan } \\
\text { sát của mình. }\end{array}$ & $\begin{array}{l}\text { Trong một lớp khoa học, các nhà } \\
\text { nghiên cứu cảm thấy họ đang cùng } \\
\text { tìm hiểu một đối tượng lớn cùng } \\
\text { nhau (các loại nghiến cứu khác nhau } \\
\text { nhưng liên kết với nhau). }\end{array}$ & $\begin{array}{l}\text { Ba lớp khoa học của } \\
\text { khoa học khám phá: } \\
\text { Toán học thuần túy, } \\
\text { triết học và các khoa } \\
\text { học cụ thể. }\end{array}$ \\
\hline $\begin{array}{l}\text { Bộ của khoa } \\
\text { học (Order of } \\
\text { science) }\end{array}$ & $\begin{array}{l}\text { Hai bộ trong cùng một lớp hay } \\
\text { phân lớp khoa học có thể khác } \\
\text { nhau về thứ bậc, cái này } \\
\text { chung hơn thì cái kia cụ thể } \\
\text { hơn. }\end{array}$ & $\begin{array}{l}\text { Trong một bộ, các nhà nghiên cứu } \\
\text { theo đuồi cùng một kiểu nghiên cứu } \\
\text { chung (nhưng làm việc với các loại } \\
\text { khái niệm khác nhau) }\end{array}$ & $\begin{array}{l}\text { Vật lý học tổng quát } \\
\text { thì chung, Vật lý học, } \\
\text { sinh học, địa lý học là } \\
\text { những khoa học cụ } \\
\text { thể hơn. }\end{array}$ \\
\hline $\begin{array}{l}\text { Họ của khoa } \\
\text { học (Family of } \\
\text { science) }\end{array}$ & $\begin{array}{l}\text { Mỗi họ khoa học có tên riêng, } \\
\text { các tạp chí chuyên ngành và } \\
\text { các hiệp hội riêng, mỗi họ } \\
\text { nghiên cứu một nhóm các } \\
\text { thực kiện. Các nhà nghiên cứu } \\
\text { trong cùng một họ khoa học } \\
\text { hiểu nhau theo một cách } \\
\text { chung và liên kêt với nhau } \\
\text { một cách tự nhiên. }\end{array}$ & $\begin{array}{l}\text { Trong cùng một họ khoa học, các } \\
\text { nhà nghiên cứu sở hữu chung những } \\
\text { khái niệm tổng quát (nhưng khác } \\
\text { biệt nhau về các kỹ năng cụ thể) }\end{array}$ & $\begin{array}{l}\text { Thiên văn học và Địa } \\
\text { lý học là những bộ̀ } \\
\text { môn khác nhau nằm } \\
\text { trong cùng một họ } \\
\text { khoa học. }\end{array}$ \\
\hline $\begin{array}{l}\text { Chi của khoa } \\
\text { học (Genus of } \\
\text { science) }\end{array}$ & \multirow{3}{*}{$\begin{array}{l}\text { Ở các nhóm này, Pierce không } \\
\text { đưa ra định nghĩa, ông viết: } \\
\text { "Tôi không thề đưa ra những } \\
\text { định nghĩa về chi và loài của } \\
\text { khoa học mà không đưa ra } \\
\text { phân loại chi tiết của các } \\
\text { nhóm này." }\end{array}$} & $\begin{array}{l}\text { Trong cùng một chi khoa học, các } \\
\text { nhà nghiên cứu có chung các kỹ } \\
\text { năng (nhưng khác biệt trong sự } \\
\text { thành thạo liên quan đến mỗi nhóm } \\
\text { thực kiện cụ thể) }\end{array}$ & $\begin{array}{l}\text { Pierce đưa ra ví dụ về } \\
\text { điện học và quang học } \\
\text { như là hai bộ môn } \\
\text { thuộc cùng một chi } \\
\text { khoa học }\end{array}$ \\
\hline $\begin{array}{l}\text { Loài của khoa } \\
\text { học } \\
\text { (Species of } \\
\text { science) }\end{array}$ & & $\begin{array}{l}\text { Loài khoa học là sự phân chia nhỏ } \\
\text { nhất mà trong đó mỗi loài vẫn còn } \\
\text { có các hiệp hội, tạp chí và mồi nhà } \\
\text { nghiên cứu đểu được được bảo chất } \\
\text { lượng bởi chúng một cách đầy đủ, } \\
\text { tức là họ thành thạo và chi tiết trong } \\
\text { mọi phần của loài. }\end{array}$ & $\begin{array}{l}\text { Ngư loại học và Côn } \\
\text { trùng học như là } \\
\text { những bộ môn thuộc } \\
\text { cùng một loài khoa } \\
\text { học. }\end{array}$ \\
\hline $\begin{array}{l}\text { Giống của } \\
\text { khoa học } \\
\text { (Variety of } \\
\text { science) }\end{array}$ & & $\begin{array}{l}\text { Các nhà khoa học trong một giống } \\
\text { khoa học tập trung vào một chủ đề } \\
\text { nghiên cứu của giống, nhưng chủ đề } \\
\text { không đủ đa dạng để thành lập các }\end{array}$ & $\begin{array}{l}\text { Pierce đưa ra ví dụ về } \\
\text { các giống khoa học } \\
\text { như: Nghiên cứu về } \\
\text { Kant (Kant học), }\end{array}$ \\
\hline
\end{tabular}




\begin{tabular}{|l|l|l|}
\hline & \begin{tabular}{l|l} 
hiệp hội và tạp chí chuyên ngành \\
riêng cho mình
\end{tabular} & $\begin{array}{l}\text { nghiên cứu về } \\
\text { Spinoza... }\end{array}$ \\
\hline
\end{tabular}

\section{4. Ưu và nhược điểm của bảng phân loại Pierce}

\subsection{Uu điểm các bảng phân loại khoa học của Pierce}

Bảng phân loại của Pierce không mang tính tùy tiện, mà có những tiêu chí cụ thể để phân loại. Những tiêu chí này đi từ một ý đồ nhất quán và thống nhất của khoa học, muốn vạch ra khung của toàn bộ khoa học như một phác thảo kiến trúc; do vậy phân loại của ông rất mạch lạc và hệ thống, ít nhất là từ nguyên tắc.

Phương pháp tiếp cận của Pierce có tính lịch sử và tính mở, ông nói rằng mọi phân loại đều phụ thuộc vào tình hình phát triển của khoa học đương thời, nên mọi bảng phân loại khoa học đều có thể được chỉnh sửa ở thời đại sau. Tinh thần lịch sử, tính mở trong phân loại khoa học của Pierce giúp cho các nghiên cứu sau bổ sung cho nghiên cứu phân loại của ông dưới ánh sáng của khoa học hiện tại.

\subsection{Nhũng hạn chế của bảng phân loại khoa học của Pierce}

Do hạn chế của thời đại và ảnh hưởng của Kant, Pierce coi Khoa học đánh giá hay Khoa học Hồi tưởng (Science of Review) là Triết học tổng hợp, tuy nhiên như chúng ta thấy Science of Review chính là Khoa học về Khoa học (Science of Science) hay Siêu khoa học (meta-science), hay Khoa học và Công nghệ luận (Science and Technology Studies). Khoa học tổng hợp này kết hợp nhiều bộ môn như triết lịch sử khoa học, tâm lý học về khoa học, xã hội học khoa học... chứ không chỉ triết học $[10,11]$.

Từ quan hệ thứ bậc tuyến tính sang quan hệ thứ bậc hồi quy. Bởi khoa học hồi tưởng (khoa học học) kế thừa từ các khoa học khám phá và khoa học thực tiễn, vậy nên sơ đồ hợp lý phải là sơ đồ thứ bậc nhưng hồi quy như sau:

\section{Khoa học mô tả}
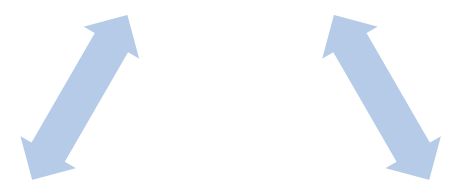
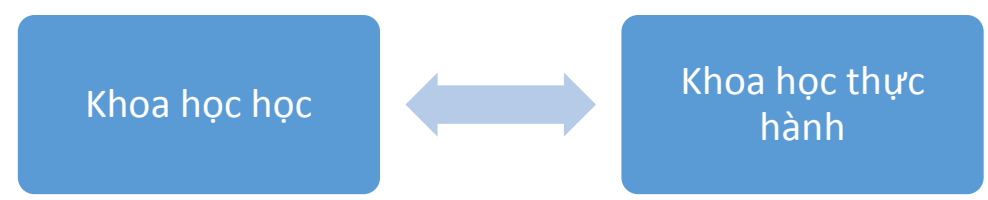

Do đặc thù lịch sử, bảng phân loại của Pierce cũng chưa thể hiện được khoa học đa bộ môn, liên bộ môn và khoa học xuyên bộ môn, vốn là đặc điểm lớn và xu hướng của khoa học thời nay. Các phân loại học của khoa học thực hành (khoa học kỹ thuật, khoa học công nghệ) cần được phân tích rõ trong bối cảnh công nghệ và những nghiên cứu về công nghệ phát triển vượt bậc hiện nay. 


\section{5. Ý nghĩa, ứng dụng của bảng phân loại khoa học của Pierce}

Phân loại khoa học giúp ích cho phương pháp nghiên cứu khoa học [10]. Nắm vững phân loại khoa học của Pierce có thể tránh được những sai lầm trong nghiên cứu khoa học. Chẳng hạn việc phân biệt về khoa học khám phá (nghiên cứu cơ bản) và khoa học thực hành (nghiên cứu ứng dụng) có thể giúp người nghiên cứu khoa học tránh được sự lầm lẫn về logic về phân loại. Tác giả Vũ Cao Đàm trong các tài liệu về phương pháp luận nghiên cứu khoa học và đánh giá nghiên cứu khoa học, thường chỉ ra các lỗi của nghiên cứu do không phân biệt được các loại hình nghiên cứu như sự bất nhất giữa mục tiêu nghiên cứu và câu hỏi nghiên cứu "Mục tiêu là nghiên cứu Giải pháp, nhưng câu hỏi nghiên cứu lại là nghiên cứu giải thích" $[12,13]$. Có thể nói, phân loại khoa học gián tiếp hoặc trực tiếp giúp cho quá trình nghiên cứu khoa học và đánh giá nghiên cứu khoa học được đúng đắn, chuẩn mực, logic hơn.

Thông tin là một yếu tố quyết định của nghiên cứu khoa học, là nguyên liệu của nghiên cứu khoa học, việc xử lý và tổ chức dữ liệu này cần những ngành Khoa học thư viện (library science) hay khoa học tổ chức về tri thức (knowledge organisation) khi tổ chức phân loại và mã hóa các bộ môn khoa học, cần có một chuẩn mực về phân loại để giúp cho các nhà nghiên cứu tra cứu, tìm kiếm dữ liệu hiệu quả hơn.

Bảng phân loại khoa học, do bộ Khoa học và Công nghệ có thể tham khảo phân loại của Pierce để điều chỉnh lại cho hợp lý hơn về mặt khoa học cũng như hiệu quả quản lý. Việc xây dựng, đánh giá, lập kế hoạch về các chiến lược, chương trình, đề tài, dự án nghiên cứu khoa học quốc gia phụ thuộc vào một bảng phân loại khoa học, nếu muốn hiệu quả và thực sự khoa học, cần đặt trên một nền tảng phân loại khoa học tường minh, vững chắc, cập nhật và phù hợp với thực tế. Các quỹ khoa học và công nghệ như Nafosted cũng cần phân biệt chính xác giữa khoa học cơ bản và khoa học ứng dụng, để tránh việc bỏ sót các đề tài trong phạm vi thẩm quyền của mình lẫn đưa vào các đề tài khoa học thuộc lĩnh vực khoa học ứng dụng, giảm lãng phí tài lực và nhân lực khoa học.

Tóm lại, phân loại khoa học của Pierce có ý nghĩa trực tiếp và gián tiếp với cả các nhà nghiên cứu lẫn nhà quản lý khoa học, bên cạnh ý nghĩa về nhận thức và văn hóa đối với khoa học.

\section{Kết luận}

Các bảng phân loại khoa học của Pierce ra đời trong một bối cảnh khoa học đặc thù, kế thừa và khắc phục các bảng phân loại khoa học trước đó. Phân loại khoa học của Pierce có logic nội tại và cân nhắc đến trình độ phát triển của khoa học nên có tính mở, và có thể đưa ra các khắc phục như bài viết chỉ ra. Phân loại khoa học của Pierce có ý nghĩa lớn lao đối với các ngành khoa học luận, quản lý khoa học và khoa học thư viện như bài viết đã điểm qua, tuy vậy đây là một chủ đề phức tạp, liên bộ môn, do đó được nghiên cứu, khai thác thêm.

\section{Tài liệu tham khảo}

[1] The Stanford Encyclopedia of Philosophy, Charles Sanders Peirce.

https://plato.stanford.edu/archives/win2018/entrie s/peirce/ 2018 (Accessed 04 December 2019)

[2] Arisbe, Paul Weiss Entry on Peirce in Dictionary of American Biography.

http://www.iupui.edu/ arisbe/menu/library/aboutc sp/Weissbio.htm (1934) (Accessed 04 December 2019)

[3] Bonifatii Kedrov, The History of Classification of the Sciences, Organon 1(1964) 165-185.

[4] Chiara Ambrosio, The Historicity of Peirce's Classification of the Sciences, European Journal of Pragmatism and American Philosophy 9 (2016) VIII-2.

[5] Francis Bacon, New Organon, translated by Do Minh Hop and Nguyen Trong Chuan, Knowledge Publisher, Hanoi, 2016. (In Vietnamese)

[6] Alex Csiszar, Broken Pieces of Fact: The Scientific Periodical and the Politics of Search in NineteenthCentury France and Britain, $\mathrm{PhD}$ Thesis, Cambridge, Mass., Harvard University, 2010.

[7] C. Hartshorne, P. Weiss, A.W. Burks (Eds.), Collected Papers of Charles Sanders 
Peirce (Vol. 1), Harvard University Press, Cambridge, 1931.

[8] Tampereen Yliopisto, Development of Peirce's classification of sciences - three stages: 1889, 1898 ,

1903.

https://people.uta.fi/ attove/peirce_syst.PDF 2003 (Accessed 04 December 2019)

[9] Tampereen Yliopisto, Charles Peirce's outline classification of sciences ('final vesion' 19021911). http://www.uta.fi/ attove/peirce_systems3.PDF 2000 (Accessed 04 December 2019)

[10] Vũ Cao Đàm, Introductionary Textbook to Science and Technology Studies, University of Social
Sciences and Humanities, Hanoi National University, 2009. (In Vietnamese)

[11] Le Viet Hung, Application of Thomas Samuel Kuhn's theory of science on science of science policy, Master Thesis on Science and Technology Management, Graduate Academy of Social Sciences, Vietnam Academy of Social Sciences, Hanoi, 2019. (In Vietnamese)

[12] Vu Cao Dam, Textbook on methodology of scientific research, Vietnam Education Publishing House Limited Company, Hanoi, 2016. (In Vietnamse)

[13] Vu Cao Dam, Evaluating scientific research, Science and Technics Publishing House, Hanoi, 2011. (In Vietnamese) 